\title{
Design and Fabrication of Economical Air Filter
}

\author{
Dr. B. Vijaya Kumar', M. Naveen², P. Kalyan², P. Bhavana², K. Nikhil² \\ 1Professor \& HOD, 2UG Student \\ 1,2Department of Mechanical Engineering, \\ 1,2Guru Nanak Institute of Technology, Ibrahimpatnam, Hyderabad, India
}

\begin{abstract}
How to cite this paper: Dr. B. Vijaya Kumar | M. Naveen | P. Kalyan | P. Bhavana | K. Nikhil "Design and Fabrication of Economical Air Filter" Published in International Journal of Trend in Scientific Research and Development (ijtsrd), ISSN: 24566470, Volume-3 | Issue-3 , April 2019, pp.1091-1095, URL: https://www.ijtsrd.c om/papers/ijtsrd23 256.pdf

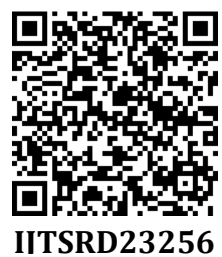

Copyright (C) 2019 by author(s) and International Journal of Trend in Scientific Research and Development Journal. This is an Open Access article distributed under the terms of the Creative Commons


Attribution License (CC BY 4.0) (http://creativecommons.org/licenses/ by $/ 4.0$ )

\section{INTRODUCTION}

An efficient air filter is a device which is embedded with different layers of permeable and fibrous materials which help in the getting rid of process, of dust particles, pollen and other material particles in the circulating air. Even some of the air filters are capable of removing the micro size particles which cannot be seen by naked eyes, particles such as the chemical and also gaseous pollutants. The above mentioned different properties of air filters help to find its application in areas with high air pollution to make it possible to filter air and provide the best possible quality of air to breath in.

The entire human made closed structures of life definitely have air as the unseen medium circulating in it. Air filters, devices used to filter air use air ionizers, fibers or elements with a static electric charge, which attract dust particles. Also air that comes into an IC Engine has to be filtered. Specific type of air filters are used to filtrate the air that comes into the combustion chamber of internal combustion engines. These type of engines and air compressors incline to make the effective use either paper, foam, or cotton filters. Oil bath filters have fallen out of favor. The air in taking technology of air filters has significantly improved since past few decades.
There are many types of air filtering materials and the ones we used in this fabrication are cotton and cloth to make this filtering procedure a more economical one. The filtering materials used in this project make the complete use of cotton and cloth properties. The four layered filtrate materials used in this project are cotton, gauze cloth, an absorbent cloth and filter cloth. Each segment of filtrate is embedded into the structure through a slot and then is fixed into a firm position.

\section{literature survey}

B. Pavan Kumar Goud, Dr. S. Chakradhara Goud, Studied on Experimental \& Numerical Study on Performance of Air Filters for Diesel Engine and then noted that the proper Maintenance of air filters will increase the fuel Economy and then the performance of Engine[4].

A.Janarthanan, R. Hariharan, V. Thirumalairaj, Dr. K. Chandrasekaran studied on the performance of air filters and concluded that air filters remove the foreign particles such as dust, dirt and soot from the intake permanently [5]. Krunal K Parmar, Shailesh M Patel studied on Air consumption and air purification through a clogged air filter and noticed that the clogged air filter results in the decrease in economical and efficient functioning of the air filter. The use of HEPA filter increases the efficient functioning of the 
air filter which matches to the European standards efficiency and also according to ASME efficiency[6].

Dipak C. Talele, Dr. Dheeraj S. Deshmukh, Dr. Prashant P. Boranare are the people studied in the development of layered filtering productions and this increases the efficiency of filtered air and these filtrates are arranged depending upon the level of filtration[7].

\section{Material and Methodology}

Materials used in our work include cotton, gauze cloth, an absorbent cloth and filter cloth. These are been arranged and placed based on their porosity values and Thread count number of respective clothes in sequential order.

\section{Cotton}

Cotton air filters are the most economical and abundantly available sources of air filter media in today's market[1]. The increase in air flow offered by cotton is more than that of any other filter media or filter paper. Thus the use of cotton provide a reusable solution of buying and throwing away disposable paper air filters which is a constant production of paper waste. These type of filters typically composed to have of about 4 to 6 layers of cotton material that is caught hold between wire mesh for strength which is then shaped the required pattern, that is resembled in one's own design. Pleat type of pattern of cotton is another arrangement of cotton in the air filter. Pleating gives the air filter more surface space and the layers of cotton create a 3D filter with filtering depth instead of filtering mostly at the top surface level. The tiny arranged cotton fibers stick out and capture particles as they pass through them. This typically designed cotton air filters to be great at the performance of filtering out particles and are great at capturing a large amount of them (dust particles) before air flow is impaired enough to need cleaning. The result obtained from such an air filtrate material is outstanding air filtration and another added advantage of it is a long service life. Such type of air filtrates also provides a good enough life time to the filter in which they are used.

\section{Gauze cloth}

A fabric with a loose open weave which is thin in its nature is termed to be known as Gauze (Thin Cloth) cloth. "Gauze"[2] its technical definition can be stated as a weave structure in which the weft yarns are arranged in pairs and are crossed before and after each warp yarn keeping the weft firmly in place. Stability of fabric, is one of the important property that a cloth should have to withstand the pressure of the incoming air, so weave structure is specifically used which is composed of fine yarns, loosely spaced.

\footnotetext{
Absorbent Cloth

An absorbent filter media works through absorbing a substance, usually a liquid or fluid as this can be concluded from its name, the dust particles gets absorbed through onto the filter media. The absorbent filter media is not that kind of filtrate where liquid particles gets separated from the solid ones, the only primary function of such a filter media is to absorb the fluid or liquid particles towards itself. This can be compared to that of the liquid absorbing property of a sponge and it do closely resemble its action when a sponge is exposed in a flow or stagnant water. Thereafter, it retains this liquid or fluid within itself until the liquid changes its structure, i.e. until it evaporates or solidifies. The concept of such a filtrate is completely distinct from that concept where
}

an absorbent filter generally works to filter out liquid substances, as. The only one condition of this type of filtering media is that it gas to be kept always in contact with the liquid.

\section{Filter cloth}

The production of filter cloth is done by means of woven or non-woven materials. The classification of non woven materials is divided as felted or membrane. The composition of the most of the cloths are either completely or partially composed of weaving of non-woven fabrics are generally in attachment to an already woven base which is technically termed as scrim. A definite repeated pattern of Woven filters of yarn are used for the fabrication of filter cloth [3]. The Felted filters are composed of randomly placed fibers which are converted into a mat. This arrangement is attached to loosely woven backing material. These type of Woven filters find their application where the system with low energy cleaning methods are used (such as shaking and reverse-air). In pulse-jet cleaning which is a higher energy cleaning system Felted fabrics usually find their application. The main motto of developing membrane filters are to achieve an efficient particle capture and also to handle flue gas conditions where high moisture and high pressure drop problems frequently occur.

Designing of Air Filter by CATIA V5

Starting of CATIA V5 is with a new name which will be displayed on the screen.

Close the product1 file and start a new file in the part design workbench.

After choosing close the file menu, then start screen of CATIA is displayed.

Start $\longrightarrow$ Mechanical Design $\longrightarrow$ select Sketcher or part design

To start a new file in the part design workbench, choose file from the menu bar. The new dialog box is displayed. After accomplishment all the necessary cuttings and modifications of the Air Filter, the ultimate model looks as shown in figure 1.

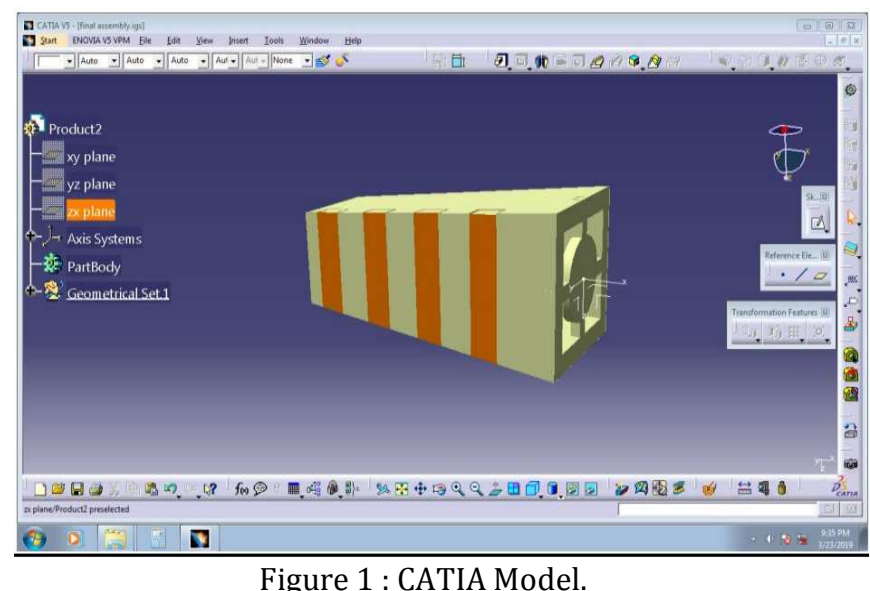

Figure 1: CATIA Model.

\section{Analysis of Air Filter by ANSYS CFX 14.5}

The final 3D Air filter Model Designed in Catia V5 is imported into Ansys CFX 14.5 for fluid flow analysis.

The steps involved during analysis are:

Starting of ANSYS CFX 14.5 has three steps to solve any type of fluid problems, which involves pre-processing, slover and 
International Journal of Trend in Scientific Research and Development (IJTSRD) @ www.ijtsrd.com eISSN: 2456-6470

post processing. All these three steps at length include Fluid Flow (CFX), Geometry, Meshing, Setup, Solution, Results. The inputs of Fluid (Air) and geometrical detail of Frustum (Truncated Square Prism) are specified in Ansys CFX software. Meshing of air filter in automatically carried on by software only for accurate results and solutions

Table 1 : Fluid Parameter

\begin{tabular}{|c|c|c|}
\hline Parameters & Air at Inlet & Air at Outlet \\
\hline Velocity $(\mathrm{m} / \mathrm{sec})$ & 0.3 & 741.33 \\
\hline Pressure $(\mathrm{Pa})$ & 8 & 40 \\
\hline $\begin{array}{c}\text { Temperature } \\
\left({ }^{\circ} \mathrm{C}\right)\end{array}$ & 25 & 34 \\
\hline Specific Heat $(\mathrm{J} / \mathrm{KgK})$ & 1020 & 1020 \\
\hline
\end{tabular}

Table 2 : Geometrical details of the filtrates

\begin{tabular}{|c|c|c|c|c|}
\hline & Cotton & $\begin{array}{l}\text { Thin } \\
\text { cloth } \\
\end{array}$ & $\begin{array}{l}\text { Thick } \\
\text { cloth } \\
\end{array}$ & $\begin{array}{l}\text { Filter } \\
\text { Paper } \\
\end{array}$ \\
\hline $\begin{array}{c}\text { Total } \\
\text { Volume } \\
\left(\mathrm{mm}^{3}\right)\end{array}$ & 332500 & 404250 & 504000 & 591500 \\
\hline $\begin{array}{l}\text { Density } \\
\left(\mathrm{kg} / \mathrm{m}^{3}\right)\end{array}$ & 450 & 300 & 500 & 250 \\
\hline $\begin{array}{c}\text { Specific } \\
\text { Heat }(\mathrm{J} / \mathrm{kgK})\end{array}$ & 1350 & 1300 & 1650 & 1400 \\
\hline $\begin{array}{c}\text { Thermal } \\
\text { Conductivity } \\
(\mathrm{W} / \mathrm{mk})\end{array}$ & 0.0455 & 0.030 & 0.130 & 0.0062 \\
\hline $\begin{array}{c}\text { Porosity } \\
(\%)\end{array}$ & 0.92 & 0.9505 & 0.9603 & 0.983 \\
\hline $\begin{array}{c}\text { Gravity } \\
\left(\mathrm{m} / \mathrm{sec}^{2}\right)\end{array}$ & \multicolumn{4}{|c|}{$X=0$} \\
\hline
\end{tabular}

Table 3 : Meshing Results

\begin{tabular}{|c|c|c|c|c|c|c|c|c|c|}
\hline \multicolumn{10}{|c|}{ Mesh statistics } \\
\hline \multirow[t]{2}{*}{ Domain Name } & \multicolumn{3}{|c|}{ I orthog. Angle } & \multicolumn{3}{|c|}{ Exp. Factor } & \multicolumn{3}{|c|}{ Aspect Ratio } \\
\hline & Min & mum & [deg] & 1 & $\operatorname{aximu}$ & & & Maxi & mum \\
\hline $\begin{array}{l}\text { Default Domain } \\
\text { cottan } \\
\text { filterpaper } \\
\text { thickcloth } \\
\text { thincloth } \\
\text { Global }\end{array}$ & & & $\begin{array}{ll}6 & \text { ok } \\
0 & \text { OK } \\
2 & \text { OK } \\
8 & 0 K \\
2 & \text { OK } \\
6 & 0 \mathrm{~K}\end{array}$ & & & $\begin{array}{ll}1 & ! \\
2 & \text { OK } \\
1 & \text { OK } \\
1 & \text { OK } \\
1 & \text { OK } \\
1 & !\end{array}$ & & & $\begin{array}{ll}75 & \text { OK } \\
1 & O K \\
1 & O K \\
1 & O K \\
1 & O K \\
75 & O K\end{array}$ \\
\hline & $\% !$ & $\% 0 \mathrm{k}$ & \%OK & $\% !$ & $\%$ ok & $\% \mathrm{OK}$ & $\% !$ & $\% 0 \mathrm{k}$ & $90 \mathrm{~K}$ \\
\hline $\begin{array}{l}\text { Defau1t Domain } \\
\text { cotton } \\
\text { filterpaper } \\
\text { thickcloth } \\
\text { thincloth } \\
\text { Globa1 }\end{array}$ & $\begin{array}{l}0 \\
0 \\
0 \\
0 \\
0 \\
0\end{array}$ & $\begin{array}{l}3 \\
0 \\
0 \\
0 \\
0 \\
2\end{array}$ & $\begin{array}{r}97 \\
100 \\
100 \\
100 \\
100 \\
98\end{array}$ & $\begin{array}{l}6 \\
0 \\
0 \\
0 \\
0 \\
4\end{array}$ & $\begin{array}{l}2 \\
0 \\
0 \\
0 \\
0 \\
1\end{array}$ & $\begin{array}{r}92 \\
100 \\
100 \\
100 \\
100 \\
95\end{array}$ & $\begin{array}{l}0 \\
0 \\
0 \\
0 \\
0 \\
0\end{array}$ & $\begin{array}{l}0 \\
0 \\
0 \\
0 \\
0 \\
0\end{array}$ & $\begin{array}{l}100 \\
100 \\
100 \\
100 \\
100 \\
100\end{array}$ \\
\hline
\end{tabular}

After all these details impaled into the software it has given accurate analytical results as shown below with figures. results and discussions

\section{Velocity Contour}

The Velocity contour for the Air Filter designed reduces from inlet to outlet gradually, this is due to increase in crosssection area as the air filter is like a divergent nozzle as shown in the figure 2.

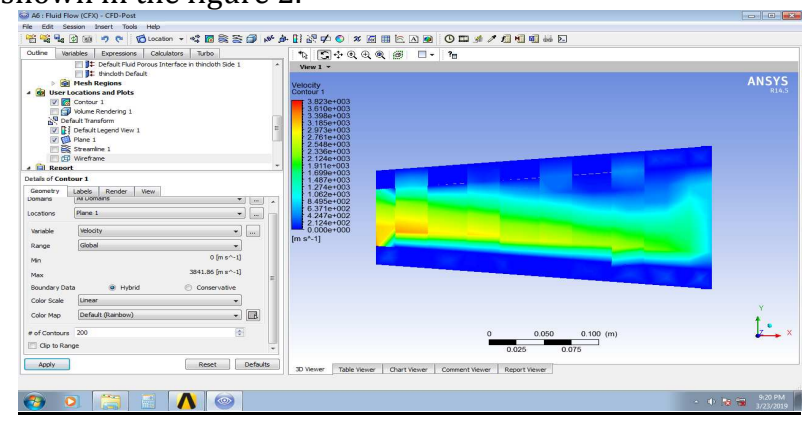

Figure 2 : Velocity Contour.

\section{Turbulence Kinetic Energy}

Turbulence of Air filter increases as the Exhaust Fan at the exit will increase the air flow which will increase the kinetic Energy resulting in turbulence of air at outlet as shown in the figure 3 .



Figure 3 : Turbulence Kinetic Energy.

\section{Total Pressure}

As the pressure is inversely proportional to velocity as the air flow passes through the filtrates the pressure gradually increases resulting maximum pressure at the outlet as shown in the figure 4.

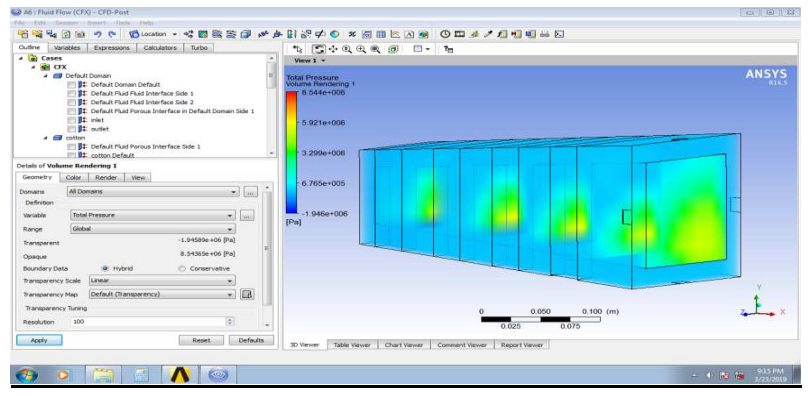

Figure 4 : Total Pressure.

\section{Eddy Viscosity}

Resistive force increases progressively as the air passes through the filtrates. As we know that viscosity is the measure of resistive force between the layer of fluid that's the reason of rise in eddy viscosity at the exit as shown in the figure 5 .

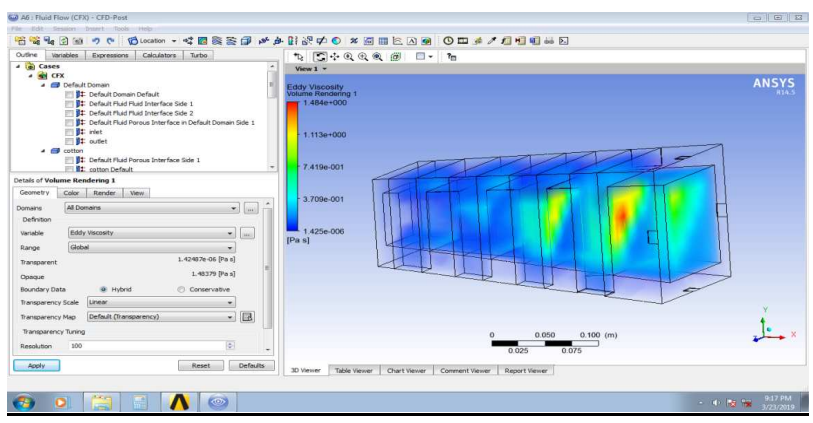

Figure 5 : Eddy Viscosity.

\section{Velocity}

The design of the Air filter resembles the Divergent nozzle so the velocity reduces slowly from inlet to outlet due to gradual increase in cross-sectional area as shown in the figure 6. 


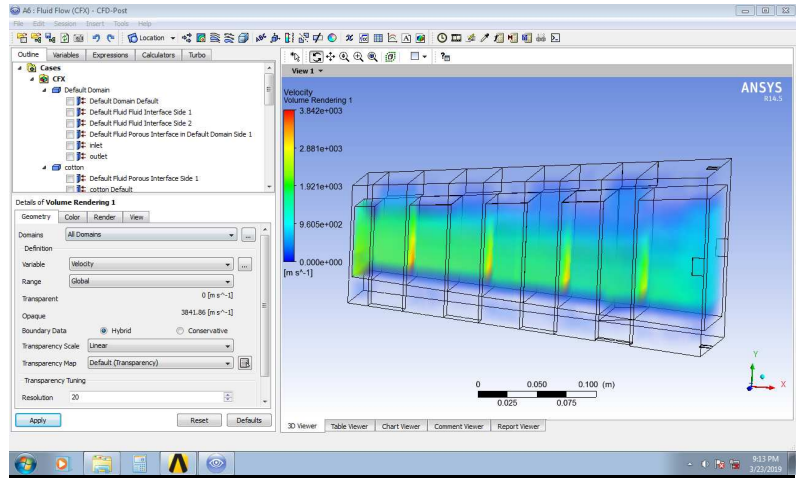

Figure 6 : Velocity.

\section{Pressure Contour}

The steam line flow of air inside the divergent nozzle will increase the pressure as the cross-sectional area increases the same situation goes on here. Pressure regularly increase as the velocity contour reduces simultaneously as shown in the figure 7 .

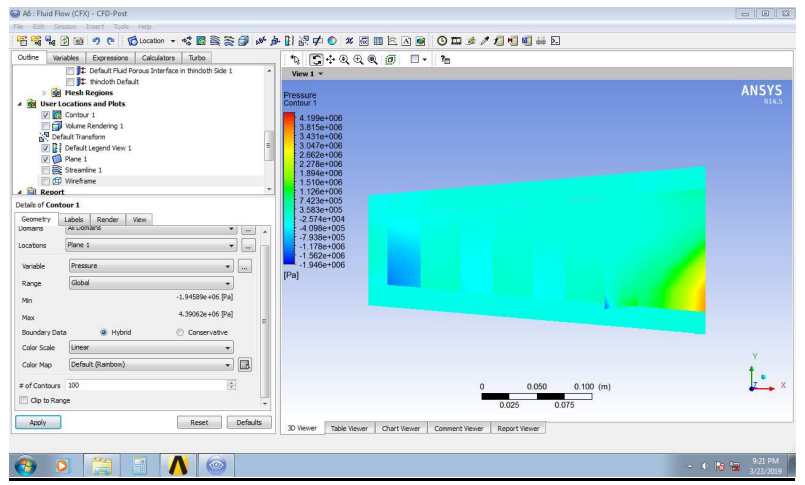

Figure 7 : Pressure Contour.

\section{Graphs Obtained For Air Flow:}

\section{Momentum and Mass}

For the air flow inside the frustum a graph is plotted taking Time and Velocity into consideration and obtained Momentum graph as shown in the figure 8.

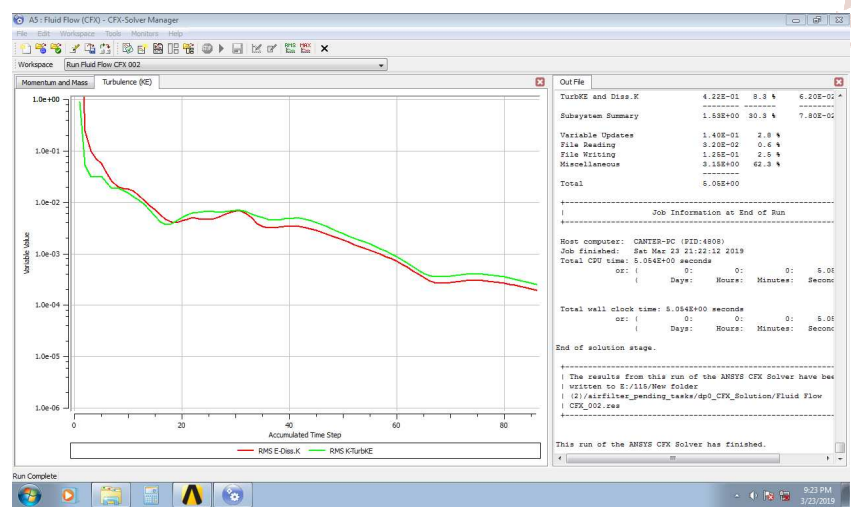

Figure 8 : Momentum and Mass.

\section{Turbulence}

The air flow inside the air filter is turbulent flow as the exhaust fan is placed at the exit of the device the Reynolds number gradually increases and the flow changes from laminar flow to turbulent flow. The graph is plotted based on Accumulated time and variable values as shown in figure 9.

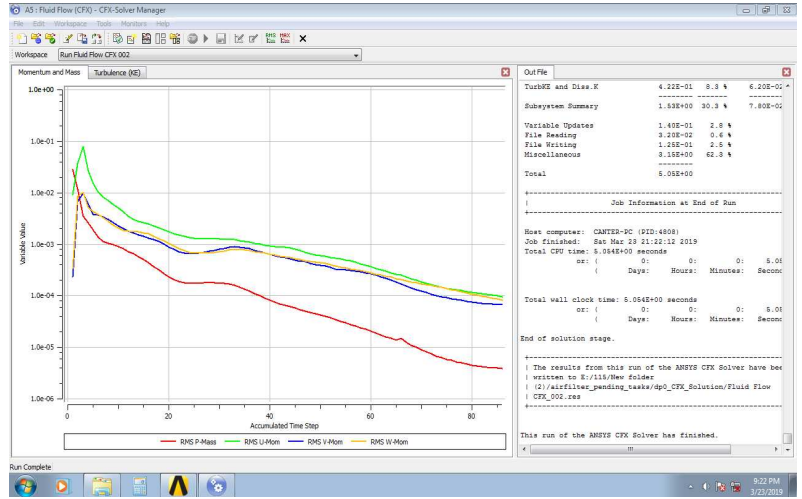

Figure 9 : Turbulence.

\section{Fabrication of Model}

The final prototype is manufactured using plywood, a open truncated square prism with one side open to atmosphere and other side with an exhaust fan is been arranged. The Frustum is been slotted at four spots for placing the filtrate as shown in figure 10.

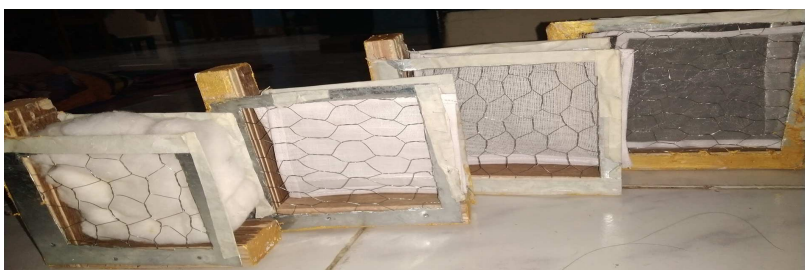

Figure 10 : Fabrication of Model.

Based on their calculated porosity percentage and Thread count numbers the filtrates are been arranged in increasing order (cotton-gauze cloth-absorbent cloth-filter cloth). The slots are being painted with golden color for simple adjustment and easy replacement of filtrates. The slots are clearly visible in the below figure 11 .

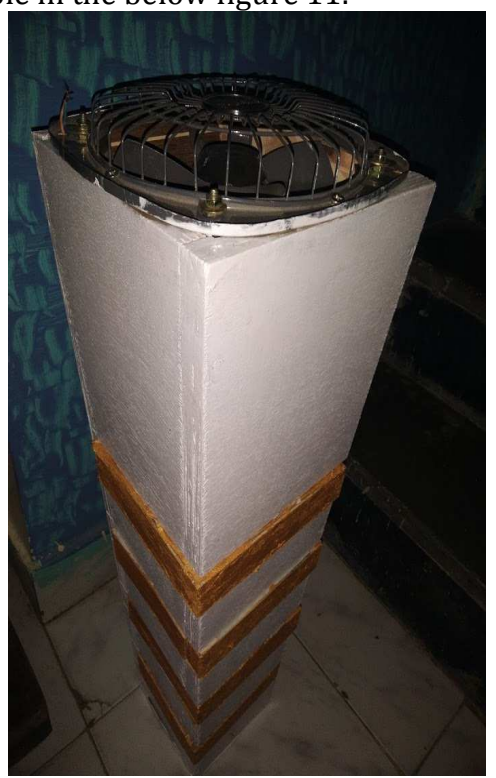

Figure 11 : Fabricated Model

The exhaust fan creates negative pressure at the inlet of the air filter and suction of air at inlet increases and gradually air passes through the filtrates on the bases of size the dust particles and obstacles will be stopped and absorbed. These dust can be easily removed by cleaning the filtrates frequently and replacing them in their respective slot. This type of Air Filter is compact, easy to handle, economical, less 
power consumption and can filter with maximum efficiency and durability. This type of Air filter does not pollute the environment by releasing harmful gases like ozone which while other air filters release and also eliminates many disadvantages of regular air filters available in market arena. As shown in figure 12 .

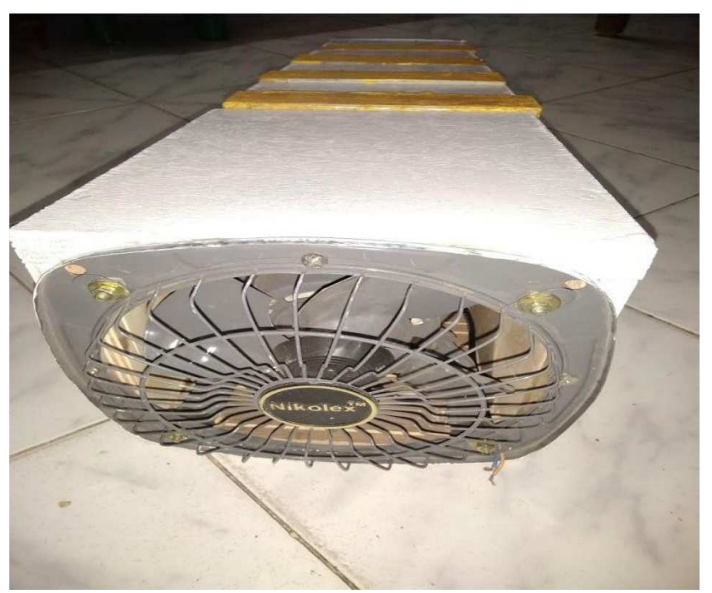

Figure 12: Prototype of Air Filter this project fetched one of the most simplest and economical air filter.

\section{References}

[1] Jean Batou (1991). Between Development and Underdevelopment: The Precocious Attempts at Industrialization of the Periphery, 1800-1870. Librairie Droz. pp. 193-196. ISBN 9782600042932.

[1] Emery, Irene (1966). The Primary Structure of Fabrics. Washington, D.C.: Thames and Hudson

[2] B. PAVAN KUMAR GOUD1,DR.S. CHAKRADHARA GOUD" Experimental and Numerical Study on Performance of Air Filters for Diesel Engine" ISSN: 2319-5967 ISO 9001:2008 Certified International Journal of Engineering Science and Innovative Technology (IJESIT) Volume 3, Issue 6, November 2014.

[3] A.Janarthanan, R.Hariharan, V.Thirumalairaj, Dr.K.Chandrasekaran-"Interfacing Of Automation In Air Filter Cleaner" IJISET - InternationalJournal of Innovative Science, Engineering \& Technology, Vol. 2 Issue 2,February 2015.

[4] Krunal K Parmar, Shailesh M Patel studied on Air consumption and air purification through a clogged air filter and noticed that the clogged air filter results in the decrease in economical and efficient functioning of the air filter. The use of HEPA filter increases the efficient functioning of the air filter which matches to the European standards efficiency and also according to ASME efficiency.

[5] Dipak C. Talele, Dr. Dheeraj S. Deshmukh, Dr. Prashant P. Boranare are the people studied in the development of layered filtering productions and this increases the efficiency of filtered air and these filtrates are arranged depending upon the level of filtration. 